\title{
SEIS SIGMA: UMA DERIVAÇÃO DO TQM?
}

\section{SIX SIGMA: A DERIVATION OF TQM?}

\author{
Marcelo Giroto Rebelato ${ }^{1}$; Andréia Marize Rodrigues ${ }^{2}$ \\ ${ }^{1}$ Universidade Estadual Paulista Júlio de Mesquita Filho - UNESP - Jaboticabal - SP - Brasil \\ mgiroto@fcav.unesp.br \\ ${ }^{2}$ Universidade Estadual Paulista Júlio de Mesquita Filho - UNESP - Jaboticabal - SP - Brasil \\ andreiamarize@fcav.unesp.br
}

\begin{abstract}
Resumo
O objetivo deste artigo é analisar se a metodologia Seis Sigma (SS) é efetivamente uma derivação do movimento Total Quality Management (TQM), ou seja, se a gênese do SS apoia-se unicamente no TQM, como afirmam os autores. Neste caminho, apresentamos um estudo comparativo entre o SS e o TQM a partir do ponto de vista de suas origens, seus dos objetivos, da ética, da estrutura e da dinâmica social de trabalho presente em cada um deles. Concluímos, a partir de todos os elementos de análise expostos, que apesar de o SS resgatar diversos elementos do TQM, tais como os objetivos e as ferramentas gerenciais, considerar o SS como uma derivação exclusiva do TQM é uma simplificação errônea e distante da realidade.
\end{abstract}

Palavras-chave: seis sigma; total quality management; origens do seis sigma.

\section{Introdução}

A globalização, que atualmente afeta as nossas sociedades, resultou em um aumento da competição econômica em âmbito mundial, mantendo acesa a consciência sobre o valor do sucesso da gerência da qualidade. A gerência da qualidade, que já era preocupação antiga no mundo dos negócios, teve com o movimento Total Quality Management (TQM) - surgido na década de 1950 um modo de compromissar a administração com a qualidade por toda a organização, focalizar nos requisitos e expectativas do clientes, reduzir a variabilidade dos processos e prevenir em vez de detectar os defeitos. A marca fundamental do TQM repousa sobre a filosofia de melhorar continuamente os processos.

Iniciado da década de 1980, portanto mais recente que o TQM, o SS também se alinha à filosofia TQM da melhoria contínua, firmado por sua vez na diretriz de que reduzir sensivelmente a variabilidade dos processos implica em melhorar a qualidade dos produtos e serviços, incrementando a satisfação do consumidor, e trazendo recompensas que podem retribuir, de forma 
amplificada, os esforços ali empenhados. O SS provocou intenso interesse dos profissionais oriundos tanto do ambiente fabril quanto do meio acadêmico diante dos primeiros relatos de desempenho obtidos por meio da sua implementação. Para Antony e Banuelas (2002), o incipiente sucesso de grandes corporações com o SS o tornou popular rapidamente.

Do exposto, pode-se pensar que o TQM seja pedra basilar do SS, isto é, o SS origina-se ou deriva do TQM. Muitos autores acreditam nisso. Para Stamatis (2000), o SS não passa de um "reempacotamento" do TQM. Conforme Flott (2000, p.43): "O TQM faz as mesmas reivindicações do SS e com justificativas".

Para Williams et al. (2004, p.604): “Temos testemunhado, nos anos recentes que se passaram, vultosos esforços de mudanças dirigidos por gerentes de alto escalão na implantação do TQM, ou em suas derivações tais como o SS, em diversas grandes corporações”.

Bendell (2006) afirma que não há fundamentalmente nada de novo no SS, trata-se de um pacote inteligente para tratar o problema da variação da variabilidade. Dahlgaard e Dahlgaard-Park (2006) concluem que o SS tem a mesma origem da filosofia de gerenciamento chamada TQM. Para Näzlung (2008), comparando-se objetivos, abordagens, ferramentas, história e fatores críticos, a conclusão é que o SS compartilha as mesmas abordagens do TQM.

Contudo, como será apresentado no desenvolvimento deste artigo, ao ampliar-se a análise da questão sobre a origem do SS além do lugar comum da abordagem processualista/funcionalista presente no discurso da grande maioria dos autores que se interessam pelo tema, torna-se quase impossível imputar a origem do SS unicamente ao TQM.

Dessa forma, este artigo tem como objetivo resgatar este debate atualmente em curso sobre SS e TQM, e avaliar sob um olhar metódico e crítico, se o SS é efetivamente uma derivação do TQM, ou seja, se a gênese do SS apoia-se unicamente no TQM, como afirmam os autores.

Este trabalho é justificado pela necessidade continuamente presente da reflexão conceitual no campo da Administração e da Engenharia de Produção. Aponta-se para a importância de se conhecer e de refletir-se tanto a respeito das práticas em um determinado campo do conhecimento quanto da construção e gênese teórica destas práticas.

\section{Metodologia de desenvolvimento}

Os discursos dos autores que abordam o tema em questão estão apoiados invariavelmente numa análise de fundamentação funcionalista (BURREL; MORGAN, 1979), que enfatiza a estrutura e os objetivos do fenômeno observado. Este fato não constitui nenhuma novidade, já que toda a Teoria Administrativa apresenta viés funcionalista (ESCRIVÃO FILHO, 1995). Apesar de 
insuficiente, devemos reconhecer que a abordagem funcionalista não é estéril e não pode ser ignorada.

Neste artigo, à visão funcionalista aliamos o ponto de vista da sociologia do trabalho, que segundo Perrot (1985), sonda alguns centros de interesse como as atitudes dos funcionários, as relações éticas e sociais na empresa e o papel dos quadros e das chefias.

Desse modo, a metodologia de desenvolvimento deste trabalho inclui elementos de análise comparativa para o entendimento das origens, dos objetivos, da ética, da estrutura e da dinâmica social de trabalho no TQM e no SS. Em sequência, as etapas metodológicas desenvolvidas percorrem:

a) Em primeiro lugar, a perspectiva histórica dos fenômenos com vistas ao entendimento da suas gêneses. Apesar das afirmações de Eckes (2001, p.13) de que o SS significa uma "viagem prática dentro de uma nova abordagem da administração", não se encontram na literatura indícios suficientes corroborando a hipótese de ser o SS uma abordagem inteiramente original. Como nos trazem McAdam e Lafferty (2004), é difícil argumentar que qualquer filosofia ou metodologia gerencial seja totalmente nova. Qualquer abordagem supostamente nova ou emergente nos negócios, na verdade, sempre possui uma linhagem histórica de suposições subjacentes ancestrais;

b) Em segundo lugar, realizamos uma análise comparativa entre os objetivos do TQM e do SS. Torna-se óbvio, no estudo do relacionamento entre os fenômenos, a necessidade de entendimento dos objetivos de cada um;

c) Em terceiro lugar, traçamos contrapontos entre as éticas implícitas aos modelos de produção em que se assentam a estruturação do trabalho de cada fenômeno. Sabemos, a priori, que a estruturação do trabalho do TQM e do SS é efetivada através do trabalho em equipe. Para Hummels e Leede (2000), desde a década passada temos testemunhado que as "organizações racionais" (organizações burocracias) de Weber geram problemas com relação à eficiência, velocidade de reação e flexibilidade. A resposta a estes entraves foi o gerenciamento por meio de equipes de trabalho. A equipe de trabalho não somente se alinha com a lógica da racionalização do trabalho, como também tem o potencial de sobrepujar algumas das falhas morais inerentes à organização racional;

d) Em quarto lugar, analisamos a questão da abrangência do TQM e do SS dentro da organização em termos da participação relativa dos funcionários dentro de cada um dos programas. O nível de disseminação entre os funcionários e o nível de comprometimento individual são elementos que revelam importantes diferenças; 
e) Em quinto lugar, contrapomos as potencialidades do TQM e do SS em termos de amplitude e profundidade das mudanças e melhorias nos processos, para identificar as diferenças entre os desafios de cada um;

f) Em sexto lugar, analisamos as metodologias em si. Realizamos o contraponto entre a inquietante "infinitude" metodológica do TQM e a proposta de metodologia estruturada do SS. Discutimos também a suspeita levantada na literatura de ser o SS uma forma de regresso atenuado ao taylorismo.

\section{A perspectiva histórica}

Conforme narram Berk e Berk (1997), o conceito de controle de qualidade (CQ) como disciplina distinta teve origem nos Estados Unidos na década de 1920. Nesta época, o CQ apenas controlava a produção de itens defeituosos nos processos industriais com a função de separar os produtos defeituosos dos produtos bons por meio da dispendiosa inspeção em massa. Este mecanismo logo mostrou-se insensato, pois não resolvia o problema dos defeitos. Apenas impedia que o produto defeituoso seguisse à frente.

Depois do surgimento da inspeção em massa, os trabalhos publicados por Shewhart, Deming, Juran, Feigenbaum, Crosby e outros indicou a possibilidade de alternativas melhores para abordar o problema dos defeitos. Seria muito mais prudente se a empresa concentrasse esforços em impedir que um produto deficiente chegasse a ser produzido.

Neste caminho, diversos estudiosos envolvidos com a teoria administrativa deixaram suas contribuições. Shewhart desenvolveu a estatística aplicada aos processos industriais durante a época da Primeira Guerra Mundial com o objetivo de controlar os processos de fabricação. A metodologia estatística de Shewhart poderia fornecer um alerta antecipado e permitir que os processos fossem ajustados antes de se fabricar um produto defeituoso. Seguidamente ao pioneirismo de Shewhart, outros pesquisadores como Deming e Juran - década de 1950 - dedicaram uma parcela significativa de seu trabalho no uso e na interpretação da estatística para melhorar a qualidade através do controle do processo, ou seja, por meio da limitação da variabilidade do processo.

Deming foi quem introduziu uma visão gerencial holística para a qualidade na empresa, e talvez seja por isso considerado o pai do TQM. Ele acreditava que o gerenciamento da qualidade não deveria concentrar-se meramente em separar os produtos defeituosos dos bons, e que a responsabilidade pela qualidade devia ser compartilhada por todos da empresa. Além disso, contrariamente à crença geral na época, que imputava toda culpa pelos erros aos trabalhadores, Deming acreditava que o funcionário era bem intencionado, e que a maioria dos problemas 
relacionados à qualidade eram induzidos pelo sistema e, portanto, não estavam associados à mãode-obra.

Inicialmente, conforme Berk e Berk (1997), os americanos não ouviram as palavras de Deming. Após a segunda guerra o General Douglas MacArthur, designado governador militar do Japão, convidou Deming para ir trabalhar no Japão como consultor administrativo. Os japoneses viram nas idéias de Deming um meio natural de evitar os erros, os desperdícios, de maximizar a produtividade e o rendimento das matérias-primas, as quais quase todas tinham de importar.

Todos conhecemos o que se sucedeu nas décadas seguintes. Os japoneses dominaram praticamente todos os mercados em que decidiram entrar: eletrônica, câmeras, automóveis, siderurgia, construção naval, motocicletas e diversos outros. A qualidade superior tornou-se um tema comum do domínio do mercado japonês. Grande parte do sucesso japonês ocorreu como resultado dos métodos estatísticos de fabricação e outras filosofias gerenciais que atualmente são conhecidas como TQM (BERK; BERK, 1997).

Os japoneses fizeram contribuições adicionais à filosofia TQM, mais notadamente nas áreas de redução da variabilidade, solução de problemas, trabalho em equipe e a identificação e satisfação das expectativas do cliente. Em poucos anos, o TQM migrou para as organizações norte-americanas e se disseminou pelo globo. Dessa forma, afirma Goldman (2005), o TQM foi a primeira palavra global que virou "moda" dentro do movimento pela qualidade.

O SS, por sua vez, é mais recente do que o movimento TQM. Conforme narra Klefsjö et al. (2001), a história do SS é bem documentada, e resumidamente, podemos dizer que sua origem se deu na gigante corporação americana de eletrônicos Motorola, onde objetivos de incrementos substanciais em todos os produtos e serviços da empresa foram estabelecidos para serem cumpridos num prazo de cinco anos.

Esta meta ambiciosa suscitou num programa (ou metodologia, segundo os especialistas) extremamente focada na redução da variabilidade dos processos e no esforço humano. O programa chamado de "Six Sigma" foi lançado em 1987. A razão do nome "Six Sigma” é a medida estatística relacionada à capacidade do processo, isto é, sua capacidade de não produzir unidades defeituosas: "seis sigmas" significa a ocorrência de um defeito em 3,4 milhão de oportunidades. Apesar de ter se iniciado na Motorola, explica Pfeifer et al. (2004), o SS foi tornado público por Jack Welch, CEO (Chief Executive Officer) da General Eletric, que com o programa economizou para a empresa um bilhão de dólares num período de dois anos.

Esta é uma diferença fundamental da origem entre o TQM e o SS. Enquanto o TQM tem origem difusa e não se consegue associá-lo a nenhuma corporação nem a um único criador (ANDERSSON et al., 2006), o SS, por outro lado, tem origem identificável e conhecida. 
A partir deste esboço histórico, podemos pensar que as raízes conceituais do TQM e do SS repousam sim sobre o mesmo alicerce teórico, já que um movimento antecede imediatamente o outro no tempo e ambos apresentam funcionalidades semelhantes. Façamos uma análise mais detalhada sobre os objetivos do TQM e do SS e vejamos se esta noção se acentua.

\section{A perspectiva dos objetivos do TQM e do SS}

Pelo exposto no item acima, pode-se compreender que o TQM foi uma resposta natural às falhas do mecanismo utilizado pelas empresas até a década de 1920 para garantir a qualidade dos produtos. O TQM surgiu como uma alternativa de maior complexidade e sofisticação à inspeção em massa. Vejamos então se o SS oferece objetivos inovadores, alternativos ou atualizados ao TQM.

Para Waldman (1994), o objetivo do TQM consiste na obtenção constante da satisfação do consumidor por meio de um sistema integrado de instrumentos, técnicas e treinamento. Isto implica a melhoria de processos organizacionais, resultando em alta qualidade de produtos e serviços.

Conforme Scheuermann et al. (1997), o TQM é uma abordagem centrada no consumidor que utiliza ferramentas e técnicas estatísticas, seguindo o esquema PDCA (Plan, Do, Check, Action) para implantar, medir e incrementar os planos pré-estabelecidos. Para Walsh et al. (2002), o TQM é um conceito muito mais amplo que as iniciativas anteriores para a qualidade, envolvendo não somente produtos, serviços e melhoria da qualidade dos processos, mas também custos, produtividade e desenvolvimento humano.

O TQM não é uma solução fácil para os problemas organizacionais, mas uma abordagem baseada na melhoria contínua e na mudança cultural. Para Dale (2003), o objetivo do TQM é produzir produtos e serviços que se adequem e, desejadamente, excedam as necessidades e expectativas dos consumidores.

O objetivo do SS, por outro lado, está na melhoria dos processos com base no entendimento das necessidades dos consumidores (HOERL, 1988). Conforme Antony (2008), os objetivos do SS são: a redução da taxas de defeitos, a redução dos custos operacionais e o incremento do valor tanto para os consumidores tanto para os acionistas.

Para Eckes (2001), a meta do método SS é melhorar a lucratividade através da redução da variação dos processos organizacionais. A essência da metodologia SS é a melhoria da eficiência e da eficácia dos processos através de rigor e disciplina. Conforme Carlivali (2007), o SS é uma estratégia de melhoria da qualidade utilizada especificamente para reduzir a variação nos processos, sejam processos de manufatura ou de serviços. Para Henderson e Evans (2000), a empresa deve implantar o SS quando desejar ser responsável pelo cliente, ser focada no consumidor, incrementar 
o desempenho de produtos e serviços e incrementar o desempenho financeiro e lucratividade do negócio.

Como podemos observar, o movimento TQM e a metodologia SS, baseiam-se na filosofia da melhoria contínua e na diretriz de que reduzir a variabilidade dos processos implica em incrementar continuamente a satisfação do consumidor. Ora, a partir do discurso dos objetivos expressos pelos especialistas, podemos afirmar que TQM e SS estão apoiados em objetivos muito semelhantes.

Se as raízes filosóficas do TQM e do SS repousam sobre a mesma fundamentação teórica e se os objetivos do TQM e do SS são tão similares, somos levados a crer com mais convicção e em consonância com a maioria dos autores, que o SS realmente é uma metodologia derivada do TQM. Passemos à análise da estruturação do trabalho de ambos e vejamos se esta idéia se corrobora.

\section{5. Ética e estruturação do trabalho}

Não restam dúvidas de que o trabalho, tanto dentro do TQM quanto no SS, é operacionalizado por meio de equipes. Isto é fácil de entender a partir da discreção potencial da estrutura em equipe - e em especial da equipe auto-gerenciada - em regular suas próprias atividades. Uma equipe auto-gerenciável têm poderes de reagir aos desafios morais que encontra pela frente.

A estrutura de equipes de trabalho traz a promessa de prover aos trabalhadores autonomia com tarefas claras e completas para que saibam como estão contribuindo para a organização e para a sociedade. A crença central é que os times auto-gerenciados permitam a simultânea autorealização dos objetivos organizacionais - em termos da "qualidade" da organização - assim como os objetivos dos trabalhadores, em termos da qualidade da vida no trabalho.

Ainda mais, a organização do trabalho por meio de equipes permite um grau mais elevado de influência por parte dos empregados no seu próprio trabalho do que um sistema de montagem convencional. Dado que a equipe pode operar com maior autonomia, ela é mais bem equipada a suportar as pressões dos gerentes de médio e de alto escalão para agir de acordo com as regras préestabelecidas.

A idéia do auto-gerenciamento carrega a promessa de abrir um diálogo entre trabalhadores, gerentes, diretores executivos, diretores não executivos, sindicatos, acionistas, etc. que dizem respeito à questões moralmente relevantes como saúde e segurança, aprendizado no trabalho, confiabilidade e qualidade do produto, tomada de decisão autônoma, e amplitude de domínio dos empregados (HUMMELS; LEEDE, 2000). 
Dessa forma, surge a pergunta: as equipes TQM servem de inspiração às equipes SS? Para responder a essa questão é preciso em primeiro lugar fazer referência ao modelo japonês de produção.

O modelo japonês repousa sobre um conceito social com foco na cooperação em trabalho reticular (keiretsu) - uma notável disseminação, dentro da empresa, do trabalho cooperativo e na confiança (FUKUYAMA, 1995). Faz-se aqui presente o poder da mobilização sobre o qual Dejours (2008, p.84) aborda: “a mobilização subjetiva de um grande número de trabalhadores, de maneira individual e coletiva".

Esta mobilização subjetiva está ligada à dinâmica do binômio contribuição-retribuição. Em troca da contribuição que traz à organização, o funcionário espera uma retribuição. No caso japonês, esta retribuição, afirma Ruas et al. (1993), se dá na forma de contrapartidas da empresa como estabilidade no emprego, maiores salários, benefícios indiretos, maior valorização profissional dentro da empresa e melhores condições de trabalho.

O modelo japonês é impulsionador de uma formulação das relações de trabalho que resulta numa maior participação do trabalhador na dinâmica da empresa, notadamente nos processos de resolução de problemas cotidianos. Neste ponto, o modelo japonês busca a aplicação generalizada do consenso (RUAS et al., 1993).

O diálogo entre trabalhadores, afirma Wilms et al. (1994), é aberto toda vez que surge uma questão sobre a melhor maneira de realizar o trabalho ou um problema a ser resolvido, que será resolvido pelo consenso. Dessa forma, toda organização deve se adaptar ao novo procedimento. Já o diálogo entre trabalhadores e escalões mais altos da organização a que Hummels e Leede (2000) se referem acima não é necessário na equipe japonesa, pois o consenso moral pré existente na "cultura fabril" é fonte de aceitação automática (por parte dos trabalhadores) das normas e valores que refletem os interesses da empresa.

A equipe TQM apoia-se na participação dos funcionários em diversos níveis da organização e os projetos partem da iniciativa dos funcionários executores das tarefas cotidianas. Desta feita, no esforço diário da melhoria contínua a equipe TQM conta mais com o conhecimento destes do que com um suporte ofertado por especialistas, isto é, a equipe TQM cria um corpo de conhecimentos difuso dentro da organização, personificado em seu pessoal, equipamentos, materiais e métodos (JHA et al., 1996).

Desse modo, a equipe TQM é a equipe identificada pela ética do modo de produção japonês. Destaca-se nessa identidade, afirma Barbosa (1999), a forte vinculação do indivíduo ao seu grupo de trabalho. $\mathrm{O}$ trabalhador japonês tem alto vínculo ao grupo a que pertence, o que se evidencia no seu entendimento sobre a importância da coletividade e aceitação das normas no ambiente de trabalho. 
Esta noção coletivista por parte do indivíduo implica no aplainamento das diferenças e no nivelamento dos comportamentos. A equipe TQM é a equipe homogênea. Apesar da crença, pelos japoneses, de que as pessoas não nascem iguais e apresentam desigualdades naturais, nenhum indivíduo tem o direito de se destacar isoladamente. Cabe à sociedade - e à empresa - aplainar as diferenças, ou seja, nivelar os comportamentos individuais. Fica implícito dessa forma, o imperativo ético de jamais imputar os resultados, positivos ou negativos, ao indivíduo isoladamente, mas sempre ao grupo a que ele pertence.

A equipe SS, por outro lado, é a equipe que se apoia na ética individualista e meritocrática, no sentido que nós ocidentais melhor a entendemos: o mérito do indivíduo como função direta das competências adquiridas e das aptidões demonstradas na sua trajetória. Para Barbosa (1999), os ocidentais, ao contrário dos japoneses, valorizam o individualismo.

A cultura ocidental, principalmente a norte-americana, crê no indivíduo autônomo e autodirigido. Desta feita, o funcionário da organização ocidental é motivado a buscar seu autodesenvolvimento e, para a organização em que está inserido, não é ilegítimo a demonstração de suas potencialidades individuais. Pelo contrário, as empresas ocidentais apreciam reconhecer o mérito individual pela realização de algo significativo.

Não é então por acaso que a equipe SS seja formada por uma "tropa de choque" organizacional, um grupo de escol que não tem origem no bottom line da corporação. Neste arranjo grupal de trabalho, há forte envolvimento e suporte da alta gerência, pois o SS utiliza uma linguagem que os CEOs conhecem bem: a linguagem financeira. Os projetos SS somente serão aprovados a partir de uma visão clara dos resultados financeiros que podem trazer à empresa. Ou seja, os projetos SS gozam de credibilidade, de modo a despertar grande interesse nos CEOs.

A equipe SS é conhecida como a equipe dos betls, cuidadosamente treinada pela empresa e potencialmente equipada para "atacar" os problemas por meio de ferramentas gerenciais avançadas e que se desdobram em projetos claramente definidos (KUMAR et al., 2008). São componentes da equipe SS (ROTONDARO, 2002):

a) O Executivo líder (da alta gerência) que conduz, incentiva e supervisiona os programas SS, verifica os benefícios financeiros alcançados com os projetos e seleciona os executivos que desempenharão o papel de campeões;

b) O Campeão, que organiza e guia o começo, o desdobramento e a implementação do SS por toda a organização e define as pessoas que irão disseminar os conhecimentos sobre o SS pela empresa;

c) O Master Black Belt, que dedica $100 \%$ de seu tempo para o SS, é preparado para a solução de problemas estatísticos, possui habilidades de comunicação e ensino, treina e instrui os 


\section{Black Belts e Green Belts;}

d) Os Black Belts, que aplicam as ferramentas em projetos específicos, recebem treinamento intensivo em técnicas estatísticas e de solução de problemas, treinam e orientam os Green Belts na condução dos grupos;

e) Os Green Belts, que tem o SS como parte de suas tarefas do dia-a-dia, auxiliam os Black Belts na coleta de dados, no desenvolvimento de experimentos e lideram pequenos projetos de melhoria em suas respectivas áreas de atuação.

Desta forma, a equipe SS alinha-se à ética norte-americana da "desigualdade substantiva". Para esta ética não se deve buscar um estado igualitário em termos de posses materiais, status e poder, pois se crê que as aptidões inatas dos indivíduos, seu esforço e sua força de vontade são manifestas em cada um em doses variadas. "Mais ainda, a diferença entre as pessoas é valorizada positivamente, pois exprime a essência de cada um de nós, enaltecendo o elemento central de todo o sistema social moderno, igualitário e individualista - o indivíduo como personalidade única e irrepetível” (BARBOSA, 1999, p.38). Dentro da ética norte-americana da desigualdade substantiva, as diferenças naturais representam a essência do indivíduo.

\footnotetext{
“...concebida como uma forma de impressão digital, implica que o indivíduo se reconheça em suas criações e que a sociedade o reconheça nelas. A medida do valor de cada um passa a estar diretamente ligada a sua produtividade objetivamente realizada, pois é através desta que se pode medir o diferencial de realização entre as pessoas. E este será positivo quanto mais os resultados apresentarem um grau de novidade, de diferença em relação aos demais" (BARBOSA, 1999, p.38).
}

Em contraste com a ética japonesa que na divisão do trabalho não se interessa pela distinção entre aquele que executa daquele que concebe, o SS, como visto, é estruturado por meio de uma hierarquia bem definida.

Cada projeto é desempenhado por equipes compostas por funcionários oriundos de diferentes áreas onde os cargos mais altos são ocupados pelos indivíduos que foram capazes de demonstrar sua competência, atitude proativa, capacidade de inovação e criatividade. Ou seja, há diferenças significativas entre os membros da equipe SS, sendo que os Master Black Belts e os Black Belts, como principais agentes responsáveis pela mudança cultural necessária ao funcionamento do time e pelo desenvolvimento dos projetos, emergem como participantes de maior destaque (REBELATO et al., 2009).

Nesta mesma linha, Klefsjö et al. (2006) advertem que existe um risco de que a estrutura belts-based tenha uma tendência inevitável de glorificar algumas pessoas, e dessa forma, não 
suportar os valores de "comprometimento de todos" do TQM.

O sistema belts-based do SS, cercado por cerimonial simbólico guerreiro inspirado no karatê koreano, o qual identifica por meio de cores o grau de maestria e domínio técnico, é estruturado com base na ética norte-americana da desigualdade substantiva, uma ética que contrasta com a ética do "nivelamento" das desigualdades do modelo japonês. Isto porque o modelo japonês realiza uma inversão ético-moral do valor ocidental "ser destacado dos demais", ou seja, a preeminência do talento cognitivo ou da criatividade é, para a equipe TQM, uma indisciplina, uma marca de personalidade arrogante, uma deslealdade à organização.

Do exposto, evidenciamos que as bases éticas e meritocráticas dos modelos que inspiram a dinâmica do trabalho no TQM e no SS não são as mesmas. Consequentemente, as equipes TQM não servem de inspiração às equipes SS. Vejamos, a partir da abrangência de ambos os programas, se encontramos novos elementos diferenciadores.

\section{Abrangência do programa}

Todos os empregados da empresa participam ativamente do TQM (CURRY; KADASAH, 2002). Esse mecanismo de participação se dá através da formação de diversas equipes, e faz-se importante destacar seu caráter de perenidade, vale dizer, as equipes seguem trabalhando continuamente.

Voltadas ao esforço de melhoria, como já dito, formam-se tantas equipes quanto forem necessárias para trabalhar em todos os setores da toda organização. Dessa forma, o TQM é um movimento organizacional amplo, largamente difundido pela organização. Está presente no TQM a ética da socialização do compromisso com a melhoria contínua que é "de todos", em todos os processos da empresa.

Para Arnheiter e Maleyeff (2005), do TQM, o SS preservou o conceito segundo o qual todos na organização são responsáveis pela qualidade dos produtos e serviços ofertados. Apesar da responsabilidade universal ser um conceito compartilhado por ambos, o TQM vai além e prescreve a participação total dos funcionários (BERK; BERK, 1997).

Podemos então indagar: com a estrutura de trabalho que lhe é inauferível, de que modo o SS poderia instrumentalizar essa "participação total”? O fato é que a disseminação do SS pela empresa não tem a mesma abrangência do TQM. O SS é tipicamente formado por poucas equipes que se formam no início do "projeto SS" e se desmembram assim que o projeto é concluído. Ou seja, as equipes SS são provisórias.

Conforme George (2002), no SS há tipicamente o envolvimento full-time de 1 a $3 \%$ da população da empresa. São equipes da elite organizacional, formadas para resolver determinado 
problema ou incrementar um indicador crítico de desempenho que esteja exibindo números indesejados. O SS desenvolve intervenções cirúrgicas vitais na empresa, ou seja, pontuais mas de grande impacto na produtividade ou rentabilidade do negócio. Contudo, o que é importante para o SS não é o número de participantes, e sim o nível de comprometimento. Black-belts e Champions devem estar disponíveis $100 \%$ de seu tempo. O SS requer que Black-belts e Champions sejam selecionados com base em seu potencial em serem futuros líderes em suas organizações.

Do ponto de vista do aprendizado organizacional podemos também inferir resultados distintos. Dado que as organizações aprendem a partir de seus indivíduos, que o aprendizado individual contribui para o aprendizado organizacional, este para a criação do conhecimento, e este, por sua vez, contribui para a inovação (MIGUEL; TEIXEIRA, 2009), podemos depreender que quanto maior a disseminação do aprendizado, maior a potencialidade de inovação na empreza. Conforme Souza (2004), não são os conhecimentos privados de cada indivíduo que estão em jogo na aprendizagem organizacional mas, sim, aqueles conhecimentos que são de algum modo compartilhados e que mobilizam a ação.

A partir das idéias expostas neste item afirmamos que o TQM não serve de inspiração ao SS. Enquanto o primeiro se inspira no trabalho de melhoria difundido pela organização e pelo caráter perene das equipes, impactanto fortemente no potencial de aprendizado organizacional, o segundo recorre ao mecanismo de projetos específicos tocados por poucas equipes de caráter provisório. Passemos à análise da questão da envergadura das melhorias para aprofundarmos nosso discernimento.

\section{Envergadura das melhorias}

O TQM é um movimento que não abarca as mudanças radicais. Alterações de processos mais impactantes e revolucionárias, como se obtém com a automação e a reengenharia, não fazem parte da ética da estabilidade e segurança do emprego promovido pelo TQM. Isto vale dizer que a melhoria contínua, elemento básico do TQM, não deve ser buscada em grande escala, mas em passos pequenos, subindo "um degrau de cada vez", com pequenas soluções/inovações incrementais, porém continuamente. Murphy (1998) expõe com precisão esta dicotomia. Enquanto o kaizen (melhoria contínua do TQM) foi criado para "consertar" pequenos defeitos, o SS foi criado para tratar "enfermidades" institucionais mais crônicas.

Desse modo, trabalhando sobre a estrutura de processos já existente na empresa, o SS permite um salto mais drástico e substancial nas operações por meio da execução de projetos "de porte" - o que alguns especialistas chamam de "melhoria de ruptura"- e através de caminhos que minimizem a perda de recursos e, é claro, incrementando ao mesmo tempo a satisfação do 
consumidor. O objetivo primário de atingir patamares de qualidade que não ultrapassem mais do que 3,4 defeitos por milhão de oportunidades, se constitui em um desafio mais ambicioso que as metas normalmente encontradas no TQM. Assim, ao contrário do TQM, o SS lança mão de uma metodologia pré-estruturada (DMAIC), e com menos temores que o TQM em alocar funcionários dedicados full time aos projetos, nem de utilizar as ferramentas estatísticas mais avançadas (LEEMORTIMER, 2006; MAGNUSSON et al., 2003; BANUELAS; ANTONY, 2002).

Conforme Banuelas e Antony (2004), o DMAIC é uma metodologia sistemática e rígida que contém as seguintes etapas: (Define) identificar quais os problemas a organização enfrenta e o que se pode melhorar; (Measure) medir o desempenho e obter dados e informações sobre o que melhorar; (Analyse) analisar as informações coletadas; (Improve) incrementar o processo através de melhorias que se materializam num novo processo com melhor desempenho; e por fim, (Control) implantar mecanismo de controle do processo para que este não se afaste do novo patamar de desempenho alcançado (BAÑUELAS e ANTONY, 2004).

O TQM revela-se mais temeroso que o SS, e a prática do benchmarking, fonte de isomorfismo organizacional (MEYER; ROWAN, 1991) e uma das ferramentas preconizadas pelo TQM, é o maior indício desse fato. Conforme Comm e Mathaisel (2000), no benchmarking é importante olhar as diferenças entre as empresas e determinar as causas dessas diferenças visando criar alternativas para eliminá-las. Ou seja, o benchmarking é essencialmente uma estratégia de assimilação ou cópia de mecanismos gerenciais e tecnológicos entre as organizações. Uma prática sustentada pelo temor de cometer erros, pois introduzir as mudanças já testadas e aprovadas pelas outras corporações é buscar a segurança “dos mares já dantes navegados”.

Concluímos, dessa forma, que TQM e SS não compartilham as mesmas trajetórias para o incremento da qualidade, e também sob este aspecto, o TQM não serve de inspiração ao SS.

\section{Metodologias}

O TQM não oferece uma proposta metodológica definida de implantação. Os principais gurus da qualidade ofertam idéias, princípios e diretrizes para a gestão e melhoria da qualidade, sem no entanto, mostrar um caminho claro e comprovadamente factível à implantação do TQM (KRÜGER, 2001). É por isso que Hellsten e Klefsjö (2000) afirmam que o TQM não contém uma única, porém inúmeras metodologias, pois requer inevitavelmente, adaptação ao contexto de cada organização. Como os retornos são difíceis de serem contabilizados, já que a antevisão dos resultados não é enfatizada pelo TQM, há a percepção de alto risco por parte da alta administração.

Para Brown et al. (1994), as empresas que implantam o TQM falham porque: 1) o envolvimento da gerência é fraco, isto é, falta apoio moral e material ao programa; 2) não são 
capazes de estabelecer suficiente envolvimento e motivação dos funcionários; 3) não provém o investimento necessário em educação e treinamento ou realizam um treinamento de má qualidade; 4) as empresas geralmente se focam nos processos em vez de buscarem os resultados. Para os autores, as falhas do TQM estão intimamente ligadas a uma lacuna de senso de propósito e direção, vale dizer, uma lacuna metodológica.

No entanto, para Kumar et al. (2008), enquanto o aspecto metodológico não é enfatizado pelo TQM, o SS, com a metodologia DMAIC, faz a ligação entre ferramentas e técnicas encadenadas num mecanismo lógico e sequencial. Ter uma infra-estrutura a priori para um programa de qualidade, afirma Eckes (2001), traz segurança aos CEOs, que não desejam mais trabalhar ad hoc sabendo que terão custos com alocação de funcionários com altos salários em pesquisas, coleta de dados, reuniões, treinamento, compra e desenvolvimento de ferramentas computacionais, instrumentação, etc.

Dessa forma, afirma Hammer (2002), o SS contém a vantagem de garantir o avanço préestabelecido para os projetos de melhoria graças à sua rigidez metodológica. Os projetos desenvolvidos pelas equipes lideradas pelos black belts duram comumente de 3 a 6 meses para se completar e podem resultar em economias entre 150 mil a 500 mil dólares para a empresa. Um black belt deve ser capaz de liderar de 4 a 6 projetos por ano. Além disso, afirma Kumar et al. (2008), enquanto o TQM é dirigido rumo à melhoria dos processos, o SS é orientado aos resultados, o que coloca claramente em foco cada centavo a ser economizado no bottom-line. Nenhum projeto SS será aprovado pela alta direção da empresa, a menos que a equipe determine as economias que com ele podem ser geradas.

Ainda sob o ponto de vista metodológico, podemos indagar: seria o SS uma reaproximação ao taylorismo?

Klefsjö et al. (2006) mencionam que a implantação do SS se inicia com um processo de treinamento e educação massivos, porém destinados a pessoas-chave dentro da organização. Desse modo, há o perigo de se criar alienação entre o staff da organização não incluído nas atividades de melhoria.

Conforme Dale et al. (2000), para pertencer à equipe SS é necessário a capacidade de entendimento da estatística, uma área não tão popular à maioria dos gerentes. Ou seja, nem todos poderão participar da equipe SS, pois a "linguagem" do SS é a "linguagem" do controle, não da participação. O próprio nome "Seis Sigma" transmite um conceito técnico que os funcionários menos capacitados, normalmente aqueles no nível hierárquico mais baixo, não possuem habilidade suficiente de compreensão.

Pode-se dizer, dessa forma, que o SS é uma forma atenuada de retorno a uma espécie de “Apogeu do cientismo dos engenheiros...uma ideologia de técnicos que intentam regular a produção 
e as relações sociais pela aplicação da ciência na vida das empresas...” (PERROT, 1985, p.37). Para o taylorismo, afirma Perrot (1985), há uma apropriação do saber em proveito dos engenheiros e do patronato, sendo que a inteligência deve deixar de estar "sob o boné do operário".

Contrastam, desse modo, a metodologia rígida do SS com as rédeas metodológicas frouxas do TQM, pois na verdade, o TQM pode ser melhor definido não propriamente como uma metodologia, mas como um movimento gerencial ou uma filosofia de gerenciamento (PETERSEN, 1999). Sob o ponto de vista metodológico o SS se afasta do TQM, apesar de muitos autores afirmarem simplisticamente que o DMAIC do SS não passa de uma retradução do PDCA de Deming. O SS aproxima-se do taylorismo na medida em que realiza a apropriação do saber a determinada "casta" organizacional, agindo como um subsistema de dominação social, o que se opõe ao sistema de socialização do conhecimento do TQM.

\section{Conclusões}

Cabe, em primeiro lugar, reafirmarmos a grande semelhança entre os objetivos do TQM e do SS. Ambos se baseiam na melhoria contínua, na prevenção das falhas, no enfoque no cliente e na responsabilidade universal pela qualidade. Entretanto, a participação e o envolvimento de todos os funcionários, objetivo preconizado pelo TQM, não faz parte da dinâmica de trabalho do SS.

Sob o ponto de vista da estruturação do trabalho, diferentes padrões de relações se fazem presentes. Apesar do TQM e do SS serem operacionalizados por meio de equipes, estas são tecnicamente muito distintas. A equipe do SS é a equipe de referência matricial, formada por funcionários oriundos de várias áreas funcionais da empresa. A equipe TQM é equipe formada pelo grupo local de trabalho. A equipe TQM é a equipe perene, que trabalha de melhoria em melhoria indefinidamente. A melhoria contínua professada pelo TQM é a pequena melhoria, sem almejar profundos "rearranjos" no processo, e como resultado, é importante dizer, sem colocar em perigo a manutenção dos empregos. A melhoria contínua atua como um instrumento de perpetuação do emprego, o que faz do TQM um "movimento do funcionário".

A equipe SS, por outro lado, é concebida assim que o projeto se inicia e se desfaz assim que o projeto é finalizado, podendo (apesar de não necessariamente) trazer grandes saltos incrementais na eficiência do processo, com bruscas rupturas ao meio social e técnico. A partir do momento em que o projeto SS se finda, aquela equipe não é mais necessária e se ganhos substanciais de produtividade foram alcançados, a empresa pode legitimamente lançar mão do downsizing, descartando a burocracia corporativa desnecessária ou em excesso. Sob este ponto de vista, o SS é o "movimento do capital". 
O indivíduo da equipe TQM, agindo sob a ética meritocrática japonesa de valorização da senioridade, do esforço e da lealdade, canaliza suas diferenças em direção ao consenso, vale dizer, na direção dos interesses do grupo. Por outro lado, o indivíduo da equipe SS, sob a ética autonomista norte-americana, canaliza seus interesses rumo a duas direções simultaneamente: aos objetivos traçados pela equipe e aos seus objetivos pessoais de demonstrar talento e potencial de realização, visando é claro, seu reconhecimento individual.

Do ponto de vista do processo decisório, a equipe TQM traduz os valores do modo de produção japonês, inibidor da expressão da criatividade e da demonstração do talento individual. A equipe SS, por outro lado, ao assumir a importância da individualidade, instrumentaliza melhor a eficiência racionalizadora, a criatividade e por que não dizer, a ousadia em "navegar longe do porto seguro".

Sob a vertente metodológica, o SS oferece uma infra-estrutura a priori, ao contrário do TQM que demanda um trabalho ad hoc de adaptação às restrições e peculiaridades de cada organização. Enquanto o SS é direcionado pela visão dos resultados finais a serem alcançados, o TQM é dirigido simplesmente à melhoria contínua. Para o TQM, a relação direta entre melhoria e resultados é automática. Para o SS, sem uma previsão matemático-financeira clara dos resultados futuros a serem atingidos, o projeto não pode seguir adiante.

Posto que os projetos SS gozam de maior credibilidade e são mais encorajadores aos dirigentes da empresa, a equipe SS tem forte apoio da alta direção. Esta garantia de suporte gerencial aliado a equipes de alta formação técnica, com domínio na aplicação de sofisticadas ferramentas estatísticas é capaz de trazer resultados em níveis muito superiores dos obtidos com o TQM.

O SS rompe com o TQM na medida em que promove uma dominação simbólica que pode confundir, pois apesar de utilizar símbolos orientais, a dominação se dá sob a ética da desigualdade substantiva ocidental. Os símbolos guerreiros (belts) do $\mathrm{SS}$, o arcabouço técnico/teórico, as descrições e análises doutas dos objetos/fenômenos, revelam o caráter de concorrência social implícita no SS, que contrastam com a ética samurai de submissão do TQM, calcada na obsequiosidade, respeito à posição das pessoas, submissão ao grupo, e busca da harmonia social. Desse modo, o SS revela-se como um álibi para o desejo de dominar simbolicamente os operários, uma forma de resgate da ideologia tecnocrática característica da administração científica do trabalho.

Concluímos, a partir de todos os elementos de análise expostos, que apesar de o SS resgatar diversos elementos do TQM, tais como os objetivos e as ferramentas gerenciais, é extremamente simplista considerar o SS uma derivação exclusiva do TQM. 


\begin{abstract}
The objective of this paper is to analyse if the Six Sigma (SS) methodology is effectively a derivation of the Total Quality Management (TQM) movement, in other words, if the origin of the SS is supported only in the TQM, as affirm the authors. In this way, we present a comparative study between the SS and the TQM from the point of view of the origins, the objectives, of the ethics, of the structure and of the social dynamic work present in each one of them. We conclude, from all the exposed elements of analysis, that in spite of SS have rescued several elements of the TQM, such as the objectives and the management tools, to consider the SS like an exclusive derivation of the TQM is an erroneous and distant simplification of the reality.
\end{abstract}

Key-words: Six Sigma, TQM, origins of Six Sigma.

\title{
Referências
}

ANDERSSON, R.; ERIKSSON, H.; TORSTENSSON, H. Similarities and differences between TQM, Six Sigma and Lean. The TQM Magazine, v.18, n.3, p.282-296, 2006.

crossef

ANTONY, J. What is the role of academic institutions for the future development of Six Sigma? International Journal of Productivity and Performance Management, v.57, n.1, p. 107-110, 2008.

cross ${ }^{\text {ref }}$

ANTONY, J; BANUELAS, R. Key ingredients for the effective implementation of Six Sigma program. Measuring Business Excellence, v.6, n.4, p.20-27, 2002.

cross ${ }^{\text {ref }}$

ARNHEITER, E. D.; MALEYEFF J. The integration of lean management and Six Sigma. The TQM Magazine, v.17, n.1, p. 5-18, 2005.

cross ${ }^{\text {ref }}$

BANUELAS, R.; ANTONY, J. Critical success factors for the successful implementation of six sigma projects in organizations. The TQM Magazine, v.14, n.2, p.92-99, 2002.

BANUELAS, R.; ANTONY, J. Six sigma ou design for six sigma? The TQM Magazine, v.6, n.4, p.250-263, 2004.

BARBOSA, L. Igualdade e meritocracia: a ética do desempenho nas sociedades modernas. Rio de Janeiro: Fundação Getúlio Vargas, 1999.

BENDELL, T. A review and comparison of six sigma and the lean organizations. The TQM Magazine, v.18, n.3, p.255262,2006

crossef

BENEDETTO, A.R. Adapting manufacturing-based six sigma methodology to the service environment of a radiology film library. Journal of Healthcare Management, v.48, n.4, p.263-280, 2002.

BERK, J.; BERK, S. Administração da qualidade total. São Paulo: IBRASA, 1997.

BROWN, M.G.; HITCHCOCK, D. E.; WILLARD, M. L. Why TQM fails and what to do about it. New York: Richard D. Irwin, 1994.

BURRELL G.; MORGAN, G. Sociological paradigms and organizational analysis. London: Heinemann, 1979.

CARlivali, P. A new path to perfection. ABA Bank Marketing, v.39, n.3, p.24-29, 2007.

COMM, C. L; MATHAISEL, D. F. X. A paradigm for benchmarking lean initiatives for quality improvement. Benchmarking: An International Journal, v.7, n.2, p.118-127, 2000. 
CURRY, A.; KADASAH, N. Focusing on key elements of TQM: evaluation for sustainability The TQM Magazine, v.14, n.4, p.207-216, 2002.

cross ${ }^{\text {ref }}$

DAHLGAARD, J. J.; DAHLGAARD-PARK, S. M. Lean production, six sigma quality, TQM and company culture. The TQM Magazine, v.18, n.3, p. 263-281, 2006.

cross ${ }^{\text {ref }}$

DALE, B. G. Managing quality. Oxford: Blackwell Publishers, 2003.

DALE, B. G.; WILliaMS, R. T.; WIELE, T. V. D. Marginalization of quality: is there a case to answer? The TQM magazine, v.12, n.4, p.266-274, 2000.

cross ${ }^{\text {ref }}$

ECKES, G. The Six Sigma Revolution: how General Electric and others turned process into profits. New York: John Wiley e Sons, 2001.

ESCRIVÃO FILHO, E. A natureza do trabalho do executivo: uma investigação sobre as atividades racionalizadoras do responsável pelo processo produtivo em empresas de médio porte. $1995.271 \mathrm{p}$. Tese(Doutorado) - Programa de Pós Graduação em Engenharia de produção, Universidae Federal de Santa catarina, Florianópolis.

FLOTT, L.W. Six-Sigma controversy. Metal Finishing, v.98, n.12, p.43-48, 2000.

cross'

FUKUYAMA, F. Trust: the social virtues and the creation of prosperity. London: Penguin, 1995.

GEORGE, M L. Lean Six Sigma: combining Six Sigma quality with Lean speed. New York: McGraw-Hill, 2002.

GOLDMAN, H. H. The origins and development of quality initiatives in American business. The TQM Magazine, v.17, n.3, p.217-225, 2005.

cross ${ }^{\text {ref }}$

HAMMER, M. Process management and future of six sigma. MIT Sloan Management Review, Winter, p.26-32, 2002.

HELLSTEN, U.; KLEFSJO, B. TQM as a management system consisting of values, techniques and tools. TQM Magazine, v.12, n.4, p.238-244, 2000.

cross'ref

HENDERSON, K M.; EVANS, J. R. Successful implementation of six sigma: benchmarking GM Company. Benchmarking: an International Journal, v.7, n.4, p.260-281, 2000.

HOERL, R.W. Six Sigma and the future of the quality profession. IEEE Engineering Management Review, v.26, n.3, p.87-94, 1988.

HUMMELS, H., LEEDE, J. Teamwork and morality: comparing Lean Production and Sociotechnology. Journal of Business Ethics, v.26, n.1, p. 75-88, 2000.

cross $^{\text {ret }}$

JHA, S.; NOORI, H.; MICHELA, J. The dynamics of continuous improvement: aligning organizational attributes and activities for quality and productivity. International Journal of Quality Science, v.1, n.1, p.19-47, 1996.

KLEFSJÖ, B.; WILKLUND, H.; EDGEMAN, R. Six sigma seen as methodology for Total Quality Management. Measuring Business Excellence, v.5, n.1, p.31-35, 2001.

cross ref

KLEFSJÖ, B; BERGQUIST, B; EDGEMAN, R. L. Six Sigma and Total Quality Management: different day, same soup? International Journal of Six Sigma and Competitive Advantage, v.2, n.2, p. 162-178, 2006.

cross ref

KRÜGER, V. Main schools of TQM: the big five. The TQM Magazine, v.13, n.3, p. 146-155, 2001.

cross ref 
KUMAR, M.; ANTONY, J.; MADU, C. N.; MONTGOMERY, D. C.; PARK, S. H. Common myths of Six Sigma demystified. International Journal of Quality e Reliability Management, v.25, n.8, p.878-895, 2008.

cross

LEE-MORTINER, A. Six Sigma: a vital improvement approach when applied to the right problems, in the right environment. Assembly Automation, v.26, n.1, p.10-17, 2006.

cross ${ }^{\text {ref }}$

MAGNUSSON, K., KROSLID, D.; BERGMAN, B. Six Sigma: the pragmatic approach. Lund, Sweden: Studentlitteratur, 2003.

McADAM, R; LAFFERTY, B. A multilevel case study critique of Six Sigma: statistical control or strategic change? International Journal of Operations e Production Management, v.24, n.5, p. 530-549, 2004.

cross ref

MEYER, J. W.; ROWAN, B. Institutionalized organizations: formal structures as myth and ceremony. IN: POWEL, W. W.; DIMAGgiO, P. J. (1991) The new institutionalism in organizational analysis. Chicago: The University of Chicago Press, p. 41-82, 1991.

MIGUEL, L. A. P.; TEIXEIRA, M. L. M. Valores Organizacionais e Criação do Conhecimento Organizacional Inovador. Revista de Administração Contemporânea, v.13, n.1, p. 36-56, 2009.

MURPHY, T. Close enough to perfect. Wards Auto World, v.34, n.8, p.5-6, 1998.

NÄSLUNG, D. Lean, six sigma and lean sigma: fads or real process improvement methods? Business Process Management Journal, v.14, n.3, p. 269-287, 2008.

cross ref

PERROT, M. Os problemas da mão-de-obra industrial. In: Sociologia do trabalho: organização do trabalho industrial. Antologia. Lisboa: A Regrado Jogo, p.13-56, 1985.

PETERSEN, P. B. Total quality management and the Deming approach to quality management. Journal of Management History, v.5, n.8, p.468-488, 1999.

cross ref

PFEIFER, T.; REISSIGER, W.; CANALES, C. Integrating six sigma with quality management systems. The TQM Magazine, v.16, n.4, p.241-249, 2004.

cross ref

REBELATO, M. G.; RODRIGUES, A. M.; RODRIGUES, I. C. Análise das lacunas presentes na integração da manufatura enxuta com a metodologia Seis Sigma. In: ENCONTRO NACIONAL DE ENGENHARIA DE PRODUÇÃO, 2009, Salvador. Anais... Salvador: ABEPRO, 2009.

ROTANDARO, G. R. Seis sigma: estratégia gerencial para melhoria de processo, produtos e serviços. São Paulo: Atlas, 2002.

RUAS, R.; ANTUNES, J. A.; ROESE, M. Avanços e impasses do modelo janonês no Braisl: observações acerca de casos empíricos. IN: HIRATA, H. Sobre o modelo japonês: autonomação, novas formas de organização e relações de trabalho. São Paulo: EDUSP, 1993.

SCHEUERMANN, L.; ZHU, Z; SCHEUERMANN, S. B. TQM success efforts: use more quantitative or qualitative tools? Industrial Management e Data Systems, v.97, n.7, p. 264-270, 1997.

cross ${ }^{\text {ref }}$

SOUZA, Y. S. Organizações de aprendizagem ou aptrendizagem organizacional. RAE-eletrônica, v.3, n.1, Art.5, jan./jun., 2004.

STAMATIS, D. H. Who needs Six Sigma, anyway? Quality Digest, May, 2000. Disponível em $<\mathrm{http}: / /$ www.qualitydigest.com/may00/html/six-sigmacon.htmlS > Acesso em 10 jan. 2010.

WALDMAN, D. A. Designing performance systems for Total Quality implementation. Journal of Organizational change implementation, v.7, n.2, p.31-44, 1994. 
WALSH, A.; HUGHES, H.; MADDOX, D. P. Total quality management continuous improvement: is the philosophy a reality? Journal of European Industrial Training, v.26, n.6, p.299-307, 2002.

cross ${ }^{\text {ref }}$

WILLIAMS, R.; WIELE, T. V. D.; IWAARDEN, J. V. TQM: why it will again become a top management issue. International Journal of Quality e Reliability Management, v.21, n.6, p.603-611, 2004.

WILMS, W.W.; HARDCASTLE, A. J.; ZELL, D. M. Cultural transformations at NUMMI. Sloan Management Review, v.20, n.3, p.99-113, 1994.

\section{Dados dos autores:}

Nome completo: Marcelo Giroto Rebelato

Filiação institucional: FCAV - UNESP - Jaboticabal

Departamento: Economia Rural

Função ou cargo ocupado: Professor

Endereço completo para correspondência (bairro, cidade, estado, país e CEP): Via de Acesso Prof.

Donato Castellane s/n - 14884-900 - Jaboticabal - SP

Telefones para contato: 16 3209-2635

e-mail: magiroto@yahoo.com.br

Nome completo: Andréia Marize Rodrigues

Filiação institucional: FCAV - UNESP - Jaboticabal

Departamento: Economia Rural

Função ou cargo ocupado: Professora

Endereço completo para correspondência (bairro, cidade, estado, país e CEP): Via de Acesso Prof.

Donato Castellane s/n - 14884-900 - Jaboticabal - SP

Telefones para contato: 16 3209-2635

e-mail: rodriguesmarize@terra.com.br 